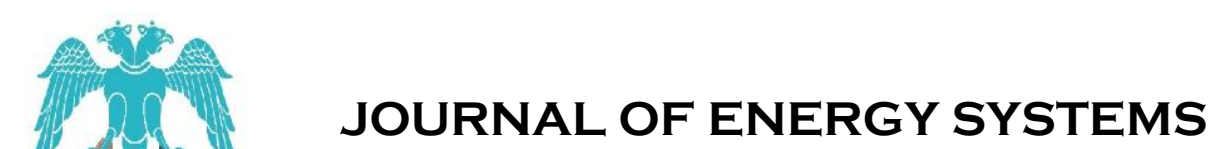

Volume 2, Issue 1

DOI: $10.30521 /$ jes.379164

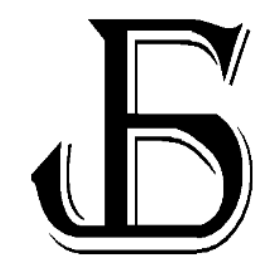

2602-2052

\title{
A numerical model for a Stirling engine
}

\author{
Salem Alaraby Ali Shufat \\ Branch of Material Science and Engineering, Institute of Natural Sciences, Kastamonu University, Turkey, \\ salemshffat5@gmail.com, orcid.org/0000-0002-2455-517X \\ Erol Kurt \\ Department of Electrical and Electronic Engineering, Faculty of Technology, Gazi University, Turkey, \\ ekurt52tr@gmail.com, orcid.org/0000-0002-3615-6926 \\ Khaled Mohamed El Hadad \\ Branch of Material Science and Engineering, Institute of Natural Sciences, Kastamonu University, Turkey, \\ khaledhadadtr@gmail.com orcid.org/0000-0002-0374-4350 \\ Aybaba Hancerlioğulları \\ Department of Physics, Faculty of Arts and Sciences, Kastamonu University, Turkey, \\ aybaba@kastamonu.edu.tr orcid.org/0000-0001-7008-480X
}

Arrived: 15.01.2018 Accepted: 13.02.2018 Published: 15.02.2018

\begin{abstract}
The concentrated solar systems by using Stirling Engines (SE) become more and more important as its renewable, cheap operational and management aspects. Thus, the usage of power sources related to SEs and their model and simulations are growing among the scientists for better efficiency and performance under different operating states. In the present study, a new SE simulation scheme has been developed by operating under Matlab/Simulink. The code mainly models and studies the thermos-mechanical performance of a beta type SE. The model includes the extensions from the solar power side under a constant temperature together with thermal and mechanical outputs. Since it has been a nonlinear model, some transient and dynamic phenomena have been taken into account to complete the system operation from start-up to full power state. The detailed model and simulation results are promising by comparing the earlier analyses even for using a semi-empirical formulation for the electricity conversion.
\end{abstract}

Keywords: CSP, Stirling engine, Modeling, Simulation,

Cite this paper as:

Shufat, S, Kurt, E, Elhadad, K, Hancerliogullari, A. A Numerical model for a Stirling engine, Journal of Energy Systems 2018; 2(1), 1-12, DOI: 10.30521/jes.379164

(C) 2018 Published by peer-reviewed open access scientific journal, JES at DergiPark (www.dergipark.gov.tr/jes) 


\section{INTRODUCTION}

Solar power is the main renewable energy source for our planet. Two types of solar energies have grown intensely for last decades: Photovoltaic (PV) and solar concentrated systems (SCSs). Since both of them require large installation areas, other renewable energy techniques can be used for small areas [1]. The solar Stirling engines can generate output power according to its dimension. Besides many factors such as the filled gas, diameters of piston and regenerator can affect the output power, drastically. The main characteristics of a SE are mechanical power generation, weight and price. Mainly the output power and dimensions are important because these two parameters play an important role to identify the system.

In the SE system designs, the main goal is to decide the optimization of output power and dimensions. Indeed, SEs are designed for an external heat source operation such as parabolic solar dishes. Differences in temperatures of two sources would affect two ends of the machine. For the high temperature part, the fossil fuels such as oil, natural gas or renewable energy sources such as solar or biomass are used frequently. According to literature, there exist a number of different working gas types such as air, helium, hydrogen, nitrogen, etc. [2-5]. The gas works on a closed thermodynamic cycle with expansion and compression cycles at high and low temperature levels [6-9].

High temperatures make SE a major option of converting solar power to electrics due to high effectiveness. From the point of effectiveness, the SE systems have a good record of solar-to grid power conversion effectiveness [10]. Besides, the modeling of those systems still interesting because of the improvement in optimization [11]. In the present study, initially an analytical modeling of a beta-type Stirling engine has been performed. Then, a simulation study following the model equations has been carried out. In section 2, the analytical expressions have been presented. Next section gives the main results in accordance with the simulation code. Mainly the pressure, power and engine speed have been considered as main parameters.

\section{MODELLING STUDY}

The model of the Stirling engine (SE) has been considered by a thermodynamic cycle of a rhombic drive beta-configuration. The engine is achieved by using a so-called ideal adiabatic model based on Schmidt theory. According to his theory, a simplified engine model can be produced by considering five volumes [12]. In the present study, a similar method has been followed in order to obtain the working space volumes of the proposed design (Fig. 1(a)). The figure shows the schematic diagram of the singlecylinder rhombic drive beta-configuration SE with a fixed acting temperature. The main working spaces for that configuration are cold - end space (i.e. compression space), regenerator space, and a hot - end space (i.e. expansion space). In that model, the movement of the displacer piston changes the volume of the expansion space. The regenerating space volume is also based on the connection between the displacer piston and displacer cylinder as seen in Fig. 1(b). The compression volume varies because of the movement of both displacer and power pistons. The prediction of alternate displacement, cyclic energy flow engine volumetric displacement, working fluid immediate mass, working fluid cycle pressure, and cyclic temperature are executed and discussed [13]. 


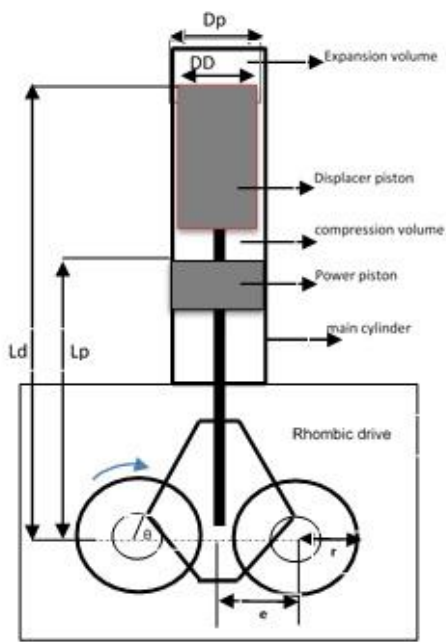

(a)

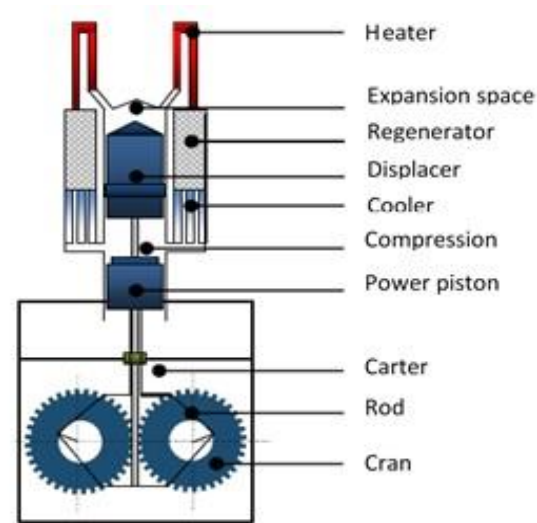

(b)

Figure 1. (a) Schematic diagram of rhombic drive beta-configuration Stirling engine. (b) Geometric parameters.

The numerical model consists of five main units. They are displacement equations, volumetric displacement equations, cyclic temperature equations, mass conservation equations, pressure equations and energy flow relations.

\subsection{Displacements Equations}

The displacement equations of the displacer and power piston connected with the rhombic drive mechanism are given below. Here, $\mathrm{x}_{\mathrm{p}}$ and $\mathrm{y}_{\mathrm{d}}$ are given as,

$$
\begin{gathered}
x(t)=\frac{x_{0}}{2}\left(1+\cos \left(\theta-\frac{\pi}{2}\right)\right) \\
y(t)=\frac{y_{0}}{2(1+\cos \theta)}
\end{gathered}
$$

Note that these expressions are standard as in Ref. [13]. The derivatives of the displacements are derived as,

$$
\begin{gathered}
\dot{x}(t)=\frac{x_{0}}{2}\left(1+\cos \left(\theta-\frac{\pi}{2}\right)\right) \\
\dot{y}(t)=\frac{y_{0}}{2(1+\cos \theta)}
\end{gathered}
$$

In above expressions, $x(t), y(t)$ are the power piston and displacer displacements as functions of time. Besides, $x_{0}, y_{0}, \theta$ are the power piston and displacer piston strokes and piston crank angle.

\subsection{Volumetric Displacements}

The volumes of the expansion and compression space are denoted by $V_{e}$ and $V_{c}$ and can be calculated in terms of displacements and cross-sectional areas of the cylinders. The volumes should also be considered in that regard. The terms of expansion and compression space volumes can also be written as [14],

$$
\begin{gathered}
V_{c}(t)=V_{d_{-} c}+x(t) A_{p}\left(y_{0}-y(t)\right) A_{d} \\
V_{e}(t)=V_{d e}+y(t) A_{d}
\end{gathered}
$$




$$
\begin{gathered}
V_{c}(t)=V_{d_{-} c}+0.5 V_{s w p}\left(1+\cos \left(\theta-\frac{\pi}{2}\right)\right)+0.5 V_{s w d}(1-\cos (\theta)) \\
V_{e}(t)=V_{d e}+0.5 V_{s w d}(1+\cos (\theta)) ;
\end{gathered}
$$

Here, while $V_{c}, V_{d c}, V_{e}, V_{d e}, V_{s w p}, V_{s w d}$ are compression space, compression space dead, expansion space, expansion space dead, power piston swept, displacer swept volumes, $A_{P}$ and $A_{d}$ are power piston contact and displacer contact areas. The derivative of volumes can be obtained as,

$$
\begin{gathered}
\dot{V}_{c}(t)=-0.5 V_{s w p} \omega \sin \left(\theta-\frac{\pi}{2}\right)+0.5 V_{s w d} \omega \sin (\theta) ; \\
\dot{V}_{e}(t)=-0.5 V_{s w d} \omega \sin \theta ;
\end{gathered}
$$

Here, $\omega$ is angular velocity in $\mathrm{rad} / \mathrm{s}$.

\subsection{Cyclic Temperature}

The gas temperature inside the compression, expansion, and regenerator spaces can be calculated using the equation of ideal gas state as follows:

$$
\begin{gathered}
T_{c}(t)=P V_{c} / R m_{c} \\
T_{e}(t)=P V_{e} / R m_{e} \\
T_{r}=\frac{\left(T_{h}-T_{k}\right)}{\ln \left(T_{h} / T_{k}\right)}
\end{gathered}
$$

The temperatures of the gas mass flow between the compression space and the cooler are determined by,

$$
\begin{gathered}
T_{c_{k}}=T_{c} \quad \text { if } m_{c_{k}} \leq 0 \\
T_{c_{k}}=T_{k} \quad \text { if } m_{c_{k}}>0
\end{gathered}
$$

Note that $m_{c k}$ is the gas mass flow rate between the compression and the cooler spaces in unit $\mathrm{kg} / \mathrm{s}$ and $T_{c}, T_{k}, T_{c r}$ are temperatures of gas in the compression, cooler spaces and the temperature of gas mass flow between the compression and the regenerator spaces in Kelvin degrees. The temperature of the gas mass flow between the heater and compression spaces can be obtained by,

$$
\begin{array}{ll}
T_{e h}=T_{h} & \text { if } m_{e h} \leq 0 \\
T_{e h}=T_{e} & \text { if } m_{e h}>0
\end{array}
$$

As in Eqs. $[14,15]$. Here meh gives the gas mass flow rate between the expansion and the heater spaces. Besides, $T_{e}, T_{h}, T_{e h}$ are the temperatures of gas in the expansion and heater spaces and the temperature of gas mass flow between the expansion and the heater spaces.

\subsection{The Mass Conservation Equations}

The conservation of mass for the control volumes can be summarized as follows:

$$
m_{e}=P V_{e} /\left(R T_{h}\right)^{\prime}
$$

where $m_{e}$ denotes the mass of working fluid in expansion space. For the compression space, 


$$
m_{c}=P V_{c} /\left(R T_{c}\right)
$$

where $m_{c}$ denotes the mass of working fluid in compression space and for the regenerator space,

$$
m_{r}=P V_{c_{-} r} /\left(R T_{r}\right)
$$

where $m_{r}$ denotes the mass of working fluid in regenerator space. For the heater and cooler parts,

$$
m_{h}=P V_{h} /\left(R T_{h}\right)
$$

where $m_{h}$ denotes the mass of working fluid in heater and

$$
m_{k}=P V_{k} /\left(R T_{k}\right)
$$

where $m_{k}$ denotes the mass of working fluid in cooler. The total mass in that case can be written as,

$$
M=m_{e}+m_{c}+m_{r}+m_{h}+m_{k}
$$

In order to simplify the simulations, one re-considers the reduced mass rates as follows:

$$
\begin{gathered}
\dot{m}_{e}=m_{e} \dot{P} / P \\
\dot{m}_{c}= \\
\left(P \hat{V}_{c}+V_{c} \dot{P} / \gamma\right) /\left(R Q_{k}\right) \\
\dot{m_{r}}=m_{r} \dot{P} / P \\
\dot{m_{r}}=m_{h} \dot{P} / P \\
\dot{m_{k}}=m_{k} \dot{P} / P
\end{gathered}
$$

\subsection{Pressure}

By recalling the ideal-gas equation,

$$
P V=M R T
$$

the fluid pressure inside the cylinder can be found by,

$$
P(t)=\frac{M R}{\left(\frac{V_{c}}{T_{k}}+\frac{V_{k}}{T_{k}}+\frac{V_{r}}{T_{r}}+\frac{V_{h}}{T_{h}}+\frac{V_{e}}{T_{h}}\right)}
$$

Here,

$$
T_{r}=\frac{\left(T_{h}-T_{k}\right)}{\ln \left(T_{h} / T_{k}\right)}
$$

Exists and the derivative of Eq. 30 yields to 


$$
\dot{P}(t)=\frac{\gamma\left(\dot{V}_{c}(t) / T_{c_{-} k}+\dot{V}_{e}(t) / T_{h \_e}\right)}{\left[V_{e} / T_{c_{k}}+\gamma\left(V_{k} / T_{k}+V_{r} / T_{r}+V_{h} / T_{h}\right)+V_{e} / T_{h_{\_} e}\right]}
$$

\subsection{Cyclic Energy Flow}

The instantaneous indicated work output in the engine can be calculated in the following form:

$$
\frac{d W_{i}}{d t}=\frac{d W_{c}}{d t}+\frac{d W_{e}}{d t}=P_{c} \frac{d V_{c}}{d t}+P_{e} \frac{d V_{e}}{d t}
$$

Finally, the indicated power can be formulated as,

$$
\begin{gathered}
W_{i}=\int_{0}^{\tau}\left(\frac{d W_{c}}{d t}+\frac{d W_{e}}{d t}\right) d t=\int_{0}^{\tau}\left(P_{c} \frac{d V_{c}}{d t}+P_{e} \frac{d V_{e}}{d t}\right) d t \\
P_{i}=W_{i} f
\end{gathered}
$$

The simulation code has been written in Matlab and it initially solves the equations in time domain. If averaged volume, power or pressure are required for the formulation, the averaged values for certain time span are taken into account.

\section{RESULTS and DISCUSSION}

The performance of the Stirling engine has been studied in different operating conditions according to various applied temperatures such as $T_{h}$ and $T_{c}$. The model can examine various applied pressures and engine speeds as in the sketched diagram of Fig. 2. By using various input values, the thermosmechanical part has been solved. $A_{t}$ the end, many functions such as displacements, volumes and pressure can be obtained as outputs.

The displacements of the power piston and displacer of $S E$ are initially shown in Fig. 3, respectively. These plots prove that the pistons work systematically with a perfect sinusoidal form and also the phase shift between the pistons are preserved by time.

Fig. 4. shows the change of the cylinder pressure and volume versus the crank angle of the engine at $700 \mathrm{rpm}$ engine speed. Note that temperature has been kept at $800^{\circ} \mathrm{C}$ for that simulation. The peak value of the cyclic pressure curve is obtained as 5.8 bars for the applied pressure of 4 bars. In the plot, $\theta=0$ corresponds to the top dead center of the displacer, which means that the massive amount of the working fluid has been in the compression volume, when the compression process has already begun. However, while the displacer moves downward, the working fluid is displaced from compression volume to the hot volume above the displacer. During this process, there exists a negative work on the piston and that process continues until piston reaches to its top dead center, which is also denoted as PTDC. 


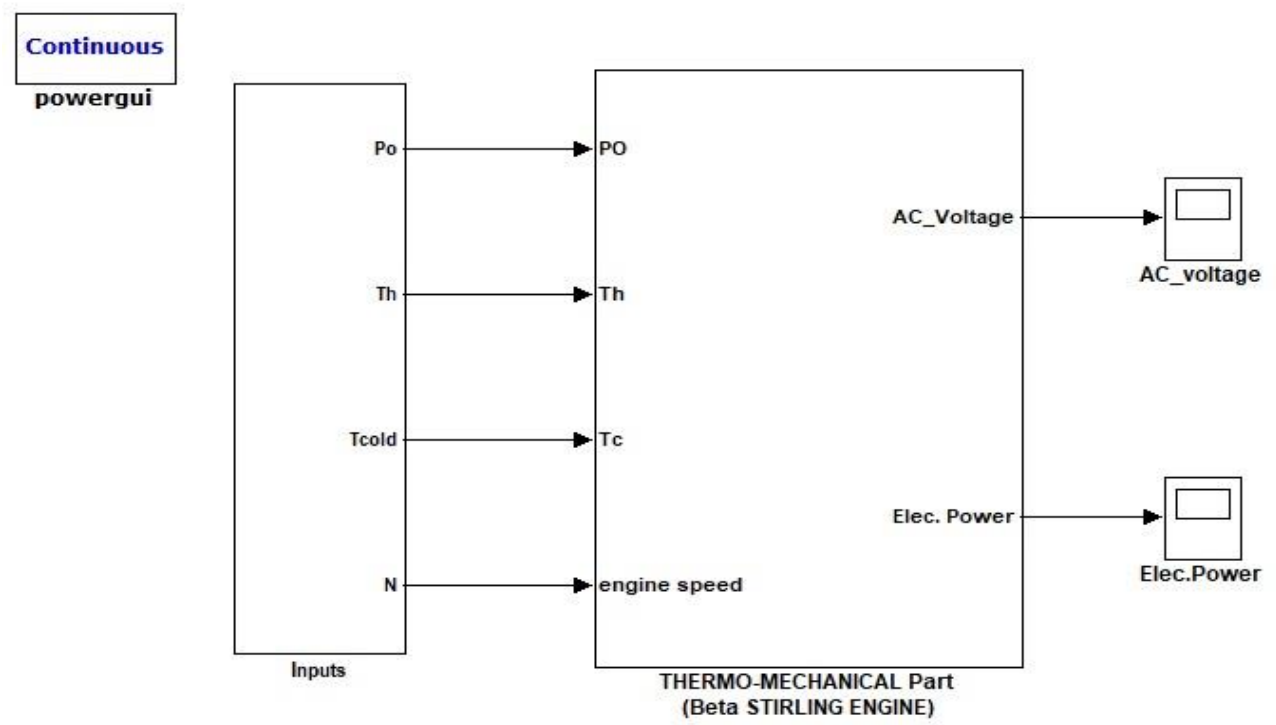

Figure 2. Simulation model of the study system

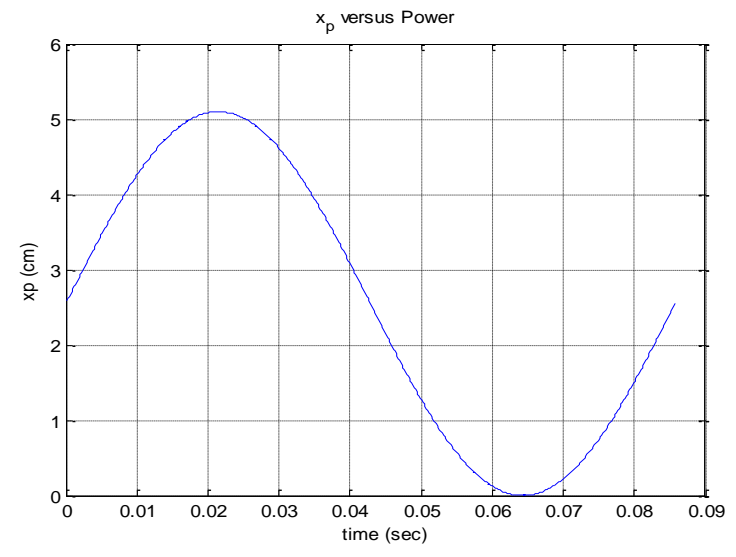

(a)

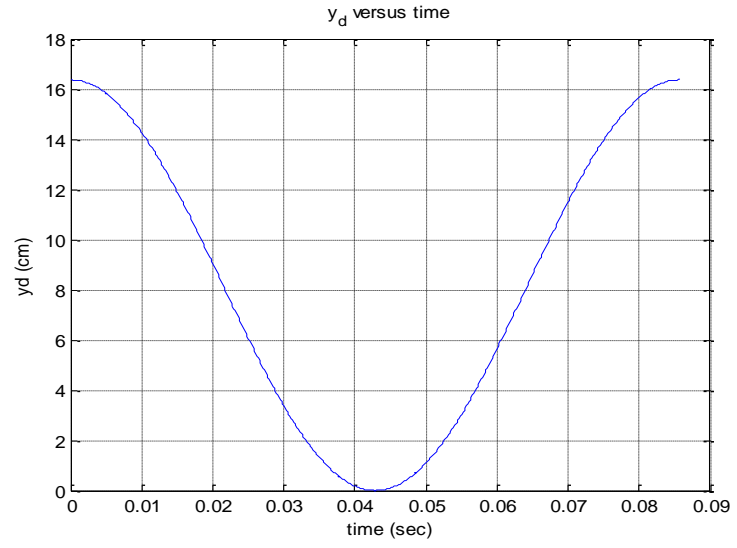

(b)

Figure 3. (a) Power piston and (b) displacer displacement versus time at $700 \mathrm{rpm}$ and $T_{h}=800^{\circ} \mathrm{C}$.

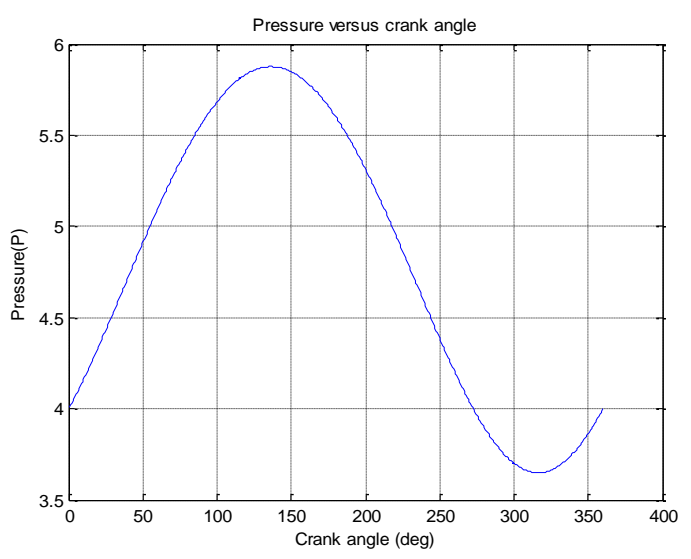

(a)

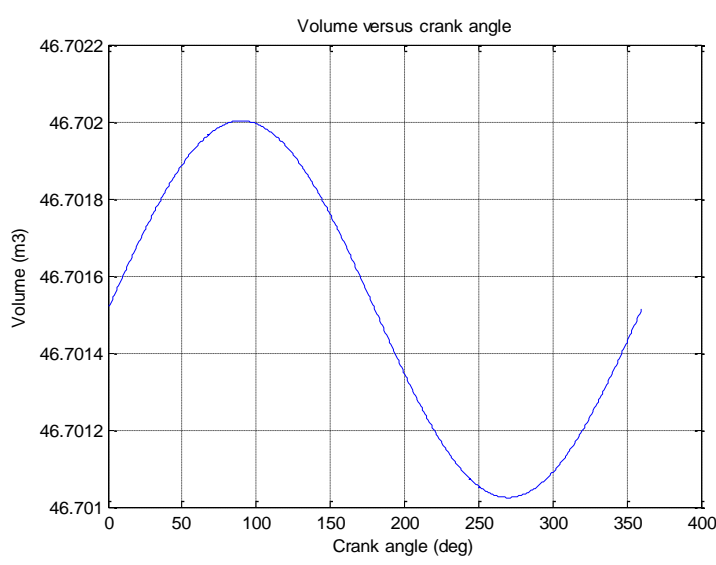

(b)

Figure 4. (a) Pressure and (b)volume versus crank angles 
Higher compression pressure requires more energy to compress the working fluid. Therefore, maximum pressure, which occurs before PTDC causes a dramatic increase in compression process, which is the main factor for the reduction of the cyclic works generation.

Fig. 5(a,b) shows the P-V diagrams for two different hot end temperatures. While the cycling area for $T_{h}=400 \mathrm{~K}$ is narrow as in Fig. 5(a), it has been enlarged for $T_{h}=800 \mathrm{~K}$ as seen in Fig. 5(b). Although, both diagrams have been obtained under 4 bars charge pressure, $700 \mathrm{rpm}$ engine speed and a $30^{\circ} \mathrm{C}$ cold end temperature, which has been kept constant by a cooled water system, the generated works differs as usual by temperature differences. For instance, when the applied temperature is $400{ }^{\circ} \mathrm{C}$, work generation has been obtained as $26.8 \mathrm{~J}$. Indeed, work generation increases up to $32.2 \mathrm{~J}$, when temperature has been raised to $800{ }^{\circ} \mathrm{C}$. The increase in the cyclic work generation has been found as $5.4 \mathrm{~J}$, while the hot end temperature is ranging from $400{ }^{\circ} \mathrm{C}$ to $800{ }^{\circ} \mathrm{C}$.

In order to explore the output power of the $S E$, Figs. 6,7 are plotted following the simulations. Note that the output power can have different values according to the engine speed under various applied pressures.

For the clarity, we have applied 1,2,3,4 and 5 bars pressure rates at two main hot end temperatures such as $600^{\circ} \mathrm{C}$ and $800^{\circ} \mathrm{C}$, respectively. It has been found that the output power increases with the engine speed up to a certain value and then it suddenly starts to decrease. Such results also exist in the literature that the SE always produces an optimal power - speed relation, when the derivation of power with respect to speed comes to "zero". Such a tendency is normal for all heat engines, since there exists a unique speed point, where the maximal power is generated. Indeed, such a relation is due to the produced mechanical torque, which depends on power and speed itself.

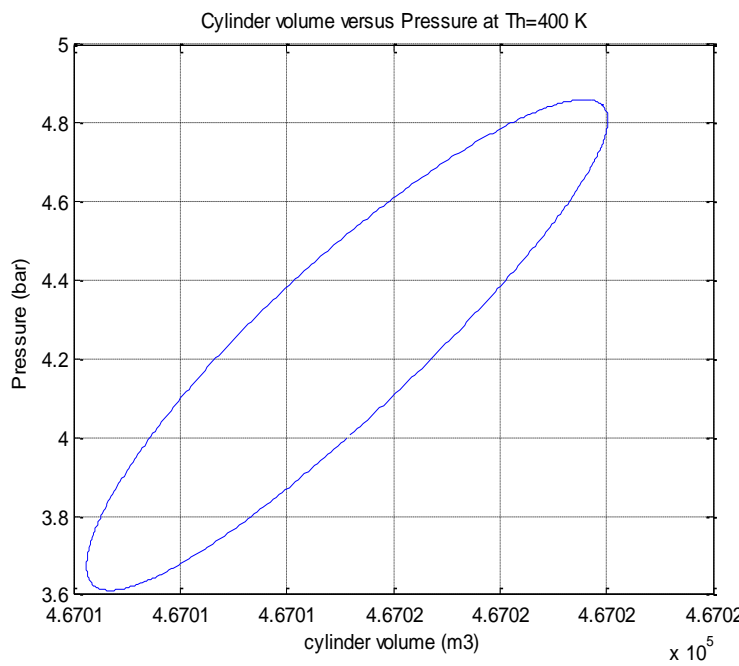

(a)

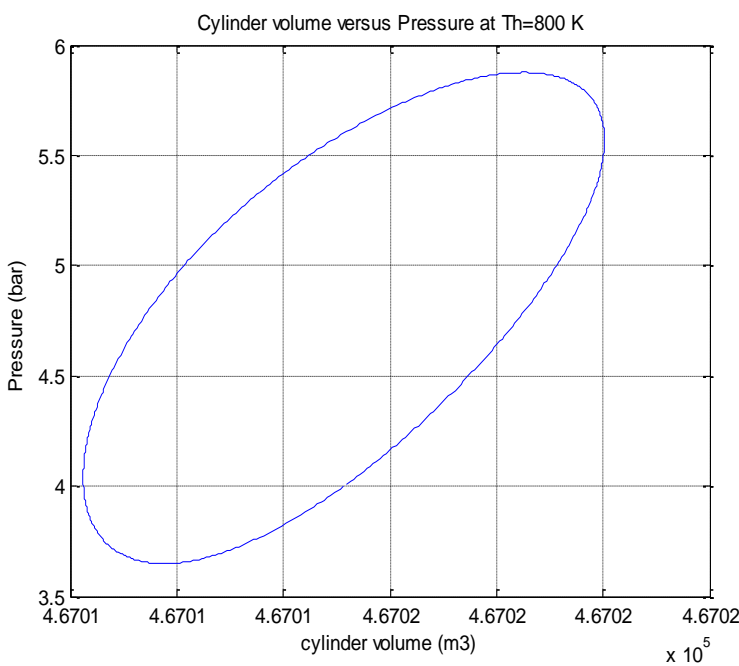

(b)

Figure 5. Pressure vs Cylinder volume 


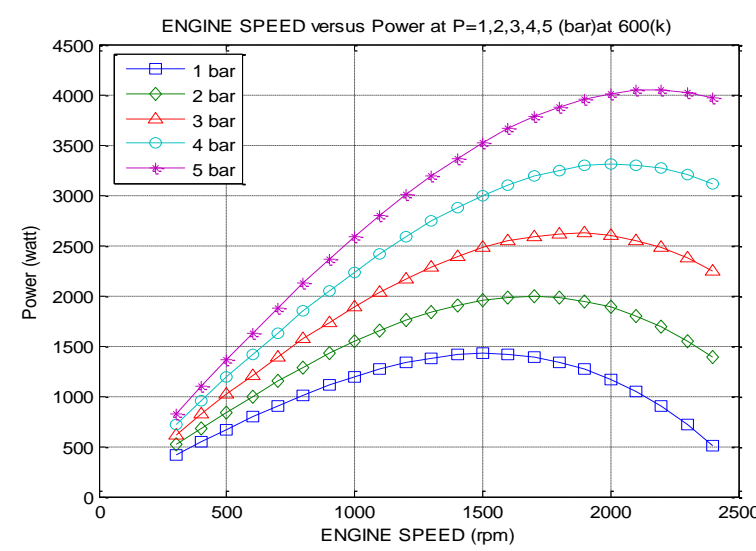

(a)

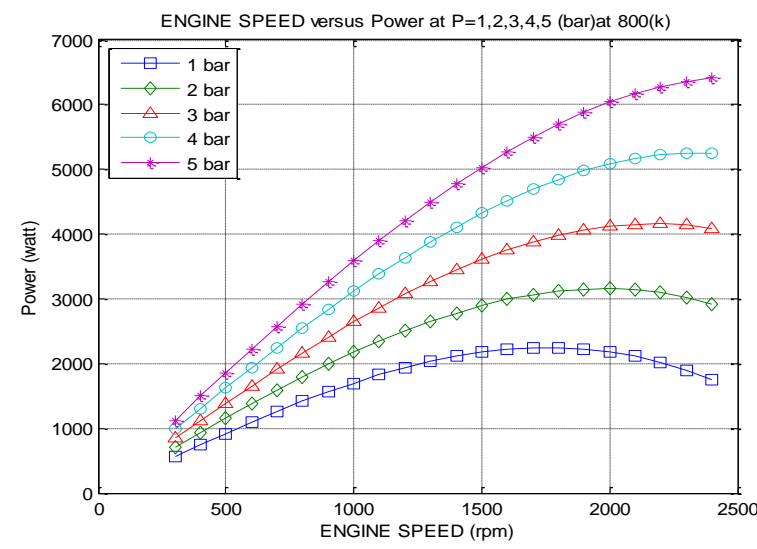

(b)

Figure 6. Power versus engine speed for various applied pressures $1,2,3,4,5$ bars at $(a) T_{h}=600^{\circ} \mathrm{K}$ and (b) $T_{h}=800^{\circ} \mathrm{K}$.

Figs. 6(a,b) proves that the increasing pressure also affects the power generation. For instance, power can be increased upto $4 \mathrm{~kW}$ from $1.5 \mathrm{~kW}$ by enhancing the pressure fivefold at $600 \mathrm{~K}$. When the hot end temperature is increased to $800 \mathrm{~K}$, the power reaches above $6 \mathrm{~kW}$. Thus, the pressure-dependence is an important finding for such engines.

In order to determine the mechanical torque variations at the hot end temperatures $600^{\circ} \mathrm{C}$ and $800^{\circ} \mathrm{C}$, the findings are summarized in Fig. 7(a,b). The highest torque (i.e. $2.6 \mathrm{Nm}$ ) has been obtained at 5 bars and $428.6 \mathrm{rpm}$ for $600^{\circ} \mathrm{C}$ hot end temperature. In addition, the torque value $3.7 \mathrm{Nm}$ is also obvious at $613 \mathrm{rpm}$ for the hot end temperature of $800^{\circ} \mathrm{C}$. It is clear from the plots that torques decay regularly by increasing speed as usual. Since Helium gas has been used in the simulations as working gas, that conventional performance has resulted due to good heating/cooling activities appearing at lower engine speeds. Note also that increasing pressure yields to higher torque values.

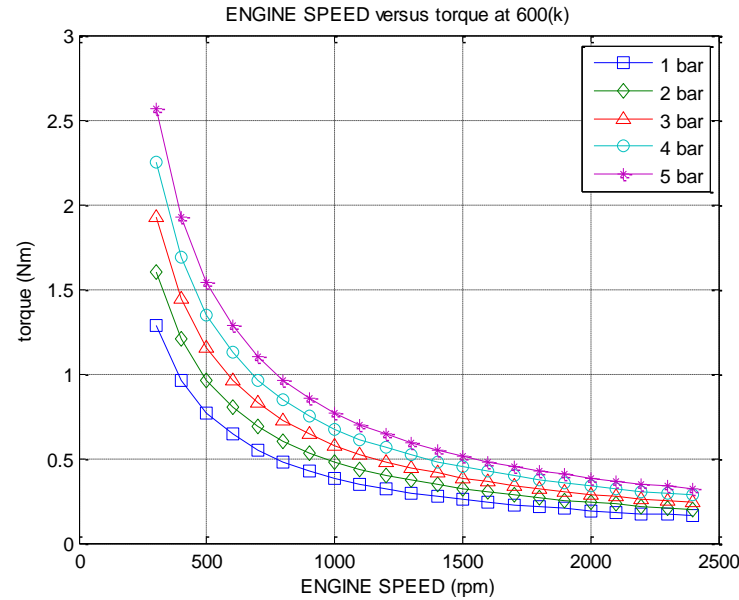

(a)

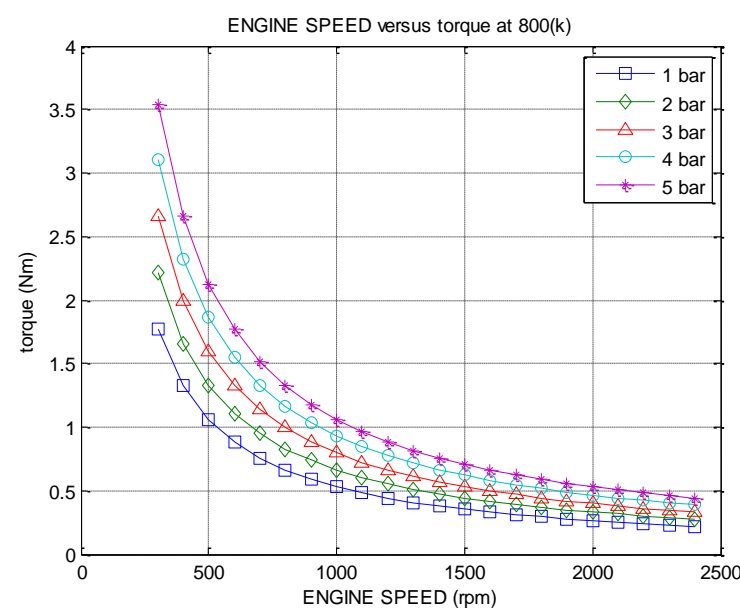

(b)

Figure 7. Torques versus engine speeds for various applied pressures at (a) $T_{h}=600 \mathrm{~K}$ and (b) $T_{h}=800 \mathrm{~K}$.

In order to clarify the power and torque relation for varying speed, Fig. 8(a) has been depicted. It is obvious that the multiplication of torque values and speeds yield to the corresponding power values as in all engines. 


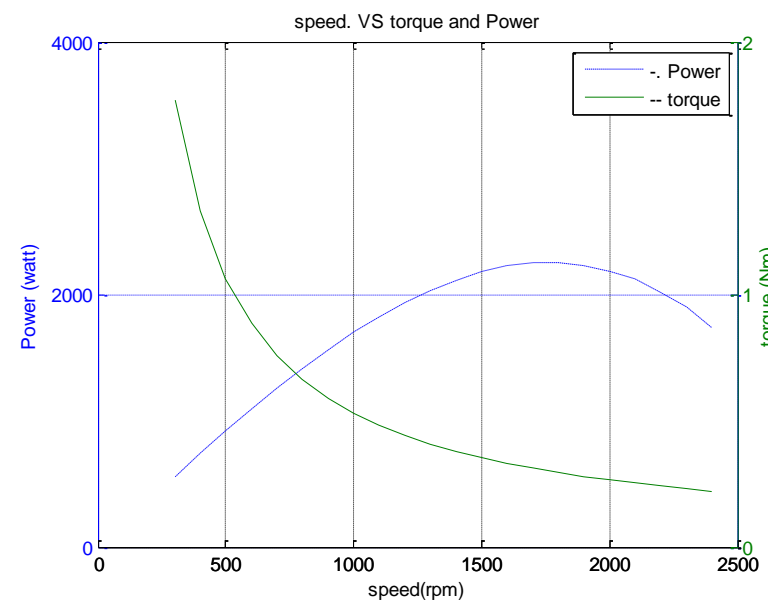

(a)

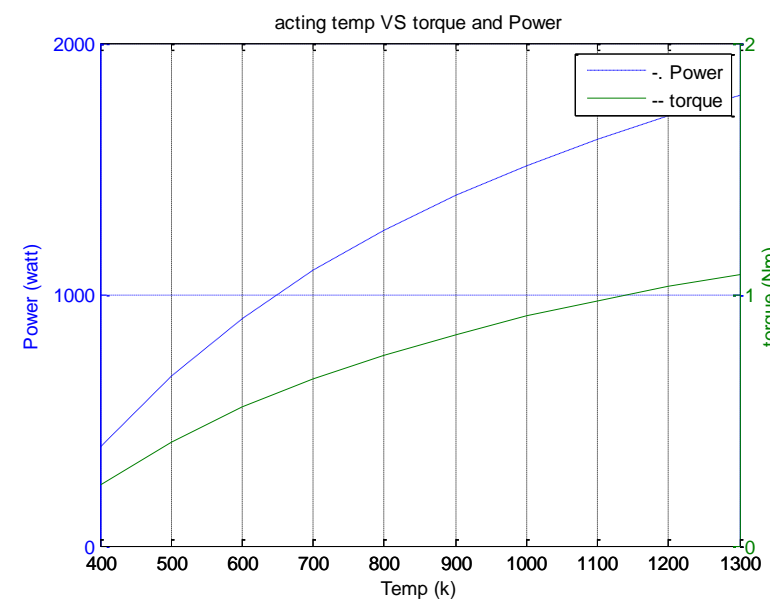

(b)

Figure 8. Output power and mechanical torque versus (a) engine speed and (b) hot end temperature.

Consequently, Fig. 8(b) shows the relation of power and torque between the hot end temperature. It has been proven that both engine power and the torque increase with the temperature. Therefore, it has been concluded that temperature is another key parameter in order to generate high powers as in the literature. The new model can be used for a variety of engine parameters and those results can be used to manufacture new machines with a desired power scale.

The application of a mathematical formula to approximate the manner of a physical system is usually accomplished in the lab. The most common such approximation is a polynomial fitting to a collection of data. This is usually done using a least squares method, which we applied to our experiment output data to derive the relation of rotational speed with output ac voltage and power for the electric generator, as shown in Fig. 9(a,b).

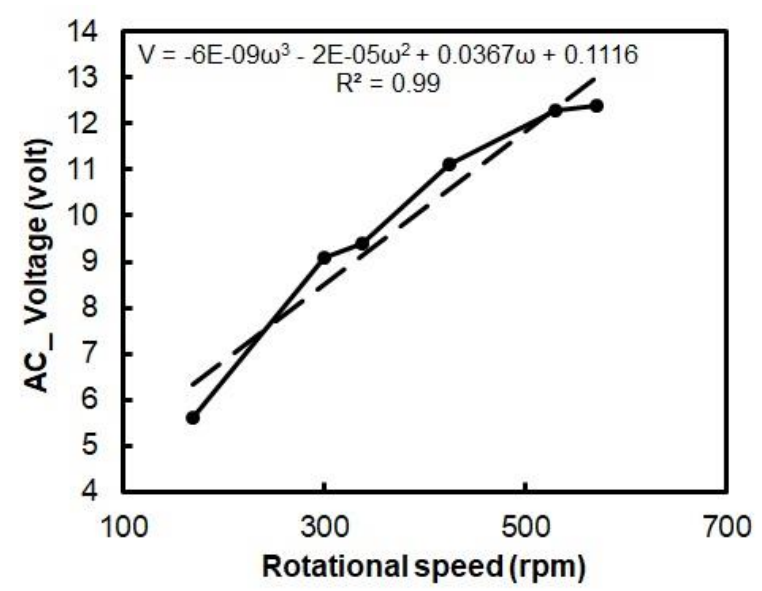

(a)

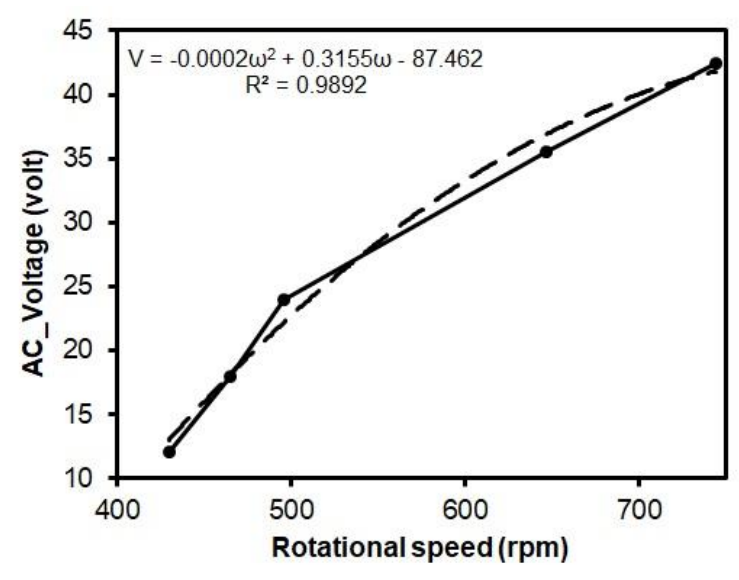

(b)

Figure 9. Fitting of generator rotational speed versus output AC voltage in the case of using (a) air media and (b) Helium gas

Resulted formula is used as a Simulink block connected to our Stirling engine model to calculate the output ac voltages and electric power as shown in Fig. 2.

Fig. 10(a,c) shows the relation between engine speed versus generated electrical rms power and Ac output voltage respectively. generally, the relation is linear as in most rotating systems. While the generated $r m s$ power is $5 \mathrm{~W}$, and output ac voltage is $\approx 5.7 \mathrm{~V}$ at $170 \mathrm{rpm}$, it reaches to $27 \mathrm{~W}, 13.5 \mathrm{~V}$ for 
$570 \mathrm{rpm}$. According to Fig. 10(b,d), the generated electrical power and the output ac voltage have been drawn with respect to rotational engine speed. Here the same linear way as in the case under air media continues, whilst the values of electric power and ac voltage become higher compared to the case with air, reach to $200 \mathrm{~W}$, and $37 \mathrm{~V}$ respectively at $750 \mathrm{rpm}$. This result indicates that power and voltage increase at least 5 times compared to the case with air.

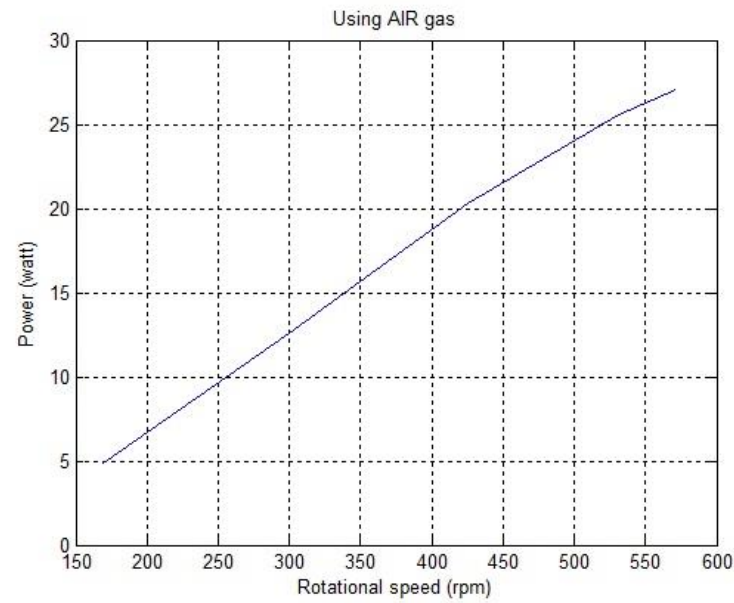

(a)

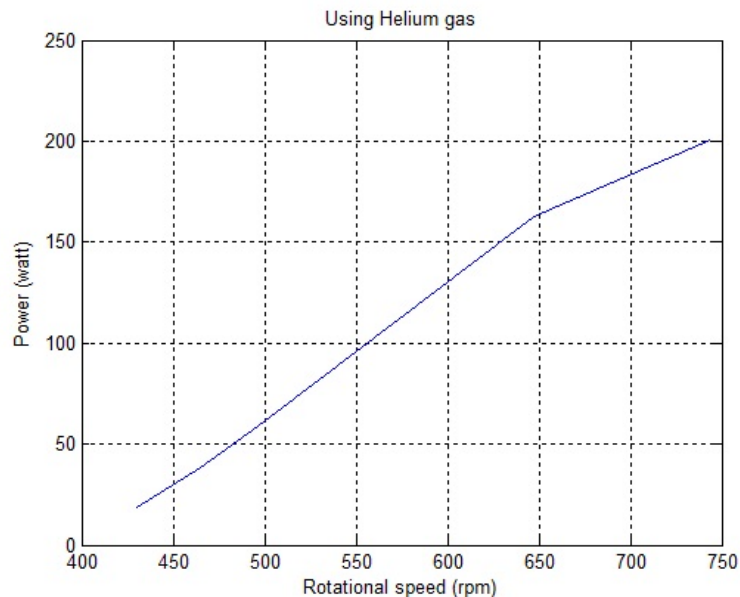

(b)

Figure. 10. Engine speed versus output power and ac voltage in the case of using (a) air (b) Helium gases, respectively.

\section{CONCLUSIONS}

In the present study, a new numerical tool has been introduced in order to estimate the parameters of a beta-type Stirling engine. The code works under Matlab/Simulink package. The findings are considered to be parallel to the literature in terms of speed, pressure, temperature and power. One can easily adjust the physical dimensions of the machine and has the output power and torque values. The designed engine can produce $1.5 \mathrm{~kW}$ power at $1 \mathrm{bar}$ and $600 \mathrm{~K}$ hot end temperature. That power can be increased further $6 \mathrm{~kW}$ by adjusting high hot end temperature and pressure. According to literature, increasing pressure can reduce the thermal efficiency of the engine. Since the input heat to the expansion cylinder is increased with the heat source temperature. Then, the rotational speed and the output power are elevated by increasing the heat source temperature. However, the temperature $T_{h}$ should be strictly restricted by the thermal expansion of the materials of the heating head and that can produce a natural limit for the output power. According to our theoretical model, we have produced a semi-empirical formulation from the real experiment, thereby one can estimate the electrical power generated by a certain rotation rate of the Stirling engine.

\section{REFERENCES}

[1] Bouzelata, Y, Kurt, E, Chenni, R, Altın. Design and simulation of a unified power quality conditioner fed by solar energy, International Journal of Hydrogen Energy, 2015; 40:15125-15380.

[2] Johromi, M, Bioki, M, Fadaeinedjad, R. Simulation of a stirling engine solar power generation system using Simulink, International Review on Modelling and Simulations, February 2012 5(1).

[3] Li, Y, Choi, S, Yang, C. Dish-Stirling Solar Power Plants: Modeling, Analysis, and Control of Receiver Temperature. IEEE transactions on sustainable energy, April 2014, 5(2):398-407.

[4] Gheith, R, Alouli, F, Ben Nasrallah, S. Study of beta type stirling engine validity of the perfect gas assumption. International Journal of Heat and Technology January 2011, 29(1):157-163.

[5] Organ, A.J., Thermodynamics and Gas Dynamics of the Stirling Cycle Machine, Cambridge University Press, UK, 1992

[6] Kongtragool, B, Wongwises, S. A review of solar-powered stirling engines and low temperature differential stirling engines, Renewable and Sustainable Energy Reviews, April 2003, 7(2):131-154. 
[7] Mishra, D, Chaudhary, S. Thermodynamic Modeling and Performance Analysis of Stirling Engine Cycle. International Journal of Innovative Research in Engineering \& Science, August 2014, 8.

[8] Cheng, C, Yu. Y, Dynamic simulation of a beta-type Stirling engine with cam-drive mechanism via the combination of the thermodynamic and dynamic models. Renewable Energy, February 2011, 36(2):714725.

[9] Cengel, Y A, Boles, M A, Thermodynamics: An Engineering Approach, McGraw-Hill Education, New York, USA, 2011

[10] Teruyuki, A, Koichi, H, Takeshi, H, Kazuhito, H. The performance of stirling engine of the free piston type enhanced with ceramics heater, MM Science Journal, December 2014, 4:537-541.

[11] Howard, D, Harley, R. Modeling of Dish-Stirling Solar Thermal Power Generation, Power Engineering Society General Meeting, IEEE 2010, July 2010, DOI:10.1109.

[12] Abbas, M, Boumeddane, B, Said, N, Chikouche, A. Dish Stirling technology: A 100 MW solar power plant using hydrogen for Algeria, International Journal of Hydrogen Energy April 2011;36:4305-4314.

[13] Zainudin, M, Abu Bakar, R, Ming, G, Ali, T, Anak, B. Thermodynamic cycle evaluation of rhombic drive beta-configuration Stirling engine, 2nd International Conference on Sustainable Energy Engineering and Application, ICSEEA 2014, 68:419 - 428

[14] Kraitong, Kwanchai. Numerical Modelling and Design Optimization of Stirling Engines for Power Production, Northumbria University (2012), Doctoral thesis.

[15] Aksoy, F, Solmaz, H, Çinar, C, Karabulu, H. 1.2kW beta type Stirling engine with rhombic drive mechanism, international journal of energy research, January 2017, 41:1310-1321 